\title{
Comparison of neonatal complications in pre-eclamptic and spontaneous preterm labour in the Persian Gulf Hospital of Bandar Abbas City, Iran, from 2011-2016
}

\author{
Seyed Hossein Saadat ${ }^{1}$, *Saeide Shahsavari ${ }^{2}$, Reyhane Saljughian Esfahani ${ }^{3}$, Fatemeh Kheiry
}

Sri Lanka Journal of Child Health, 2020; 49(3): 240-245

\begin{abstract}
Introduction: Pre-eclampsia is an important disease that affected $3.7 \%$ of infants and led to $18 \%$ of maternal deaths. In addition to maternal complications, fetal complications are also a major contributor to pre-eclampsia.
\end{abstract}

Objectives: To evaluate the neonatal outcome of preterm labour (PTL) due to pre-eclampsia and compare its complications with those of spontaneous PTL.

Method: A cross-sectional study was carried out on 190 cases of PTL using a randomized sampling method, in which 94 pregnant women with preeclampsia and 96 women with spontaneous PTL participated. Infant characteristics, including weight, height, head circumference, as well as respiratory disorders, Apgar score, jaundice, and mortality were recorded from medical files. Statistical analysis was done using SPSS ver. 20 via t-test, and Chi-squared test.

Results: The mean ages of mothers with preeclampsia and spontaneous PTL were 27.76 \pm 7.06 and $26.94 \pm 4$ years, respectively. The numbers of

\footnotetext{
${ }^{1}$ Assistant Professor, Neonatologist, Faculty of Medicine, Clinical Research Development Centre of Children's Hospital, Hormozgan University of Medical Sciences, Bandar Abbas, Iran, ${ }^{2}$ Assistant Professor, Faculty of Medicine, Fertility and Infertility Research Centre, Hormozgan University of Medical Sciences, Bandar Abbas, Iran, ${ }^{3}$ Faculty of Medicine, Hormozgan University of Medical Sciences, Bandar Abbas, Iran, ${ }^{4}$ PhD Candidate in Nursing, Student Research Committee, School of Nursing and Midwifery, Shiraz University of Medical Sciences, Shiraz, Iran

*Correspondence: Saeide.shahsavari@yahoo.com

(iD)

orcid.org/ 0000-0003-1968-9082
}

(Received on 08 September 2019: Accepted after revision on 11 November 2019)

The authors declare that there are no conflicts of interest

Personal funding was used for the project.

Open Access Article published under the Creative

Commons Attribution CC-BY (c) (P) hospitalisation days in neonatal intensive care unit (NICU), birth weights, Apgar scores at 1 and 5 minutes, head circumference, and jaundice were significantly different in the two groups. However, respiratory distress, number of infant deaths, and the length of the infants were not significantly different in the two groups.

Conclusions: In this study on preterm infants, preeclampsia had a significant impact on NICU hospitalisation rate, length of stay in NICU, Apgar scores in first and fifth minutes, the incidence of jaundice, weight, and head circumference at birth, but not on the length of the baby or respiratory distress.

http://dx.doi.org/10.4038/sljch.v49i3.9141

(Key words: Pre-eclampsia, preterm labour, neonates)

\section{Introduction}

Pre-eclampsia is defined as the incidence of hypertension greater than 140/90 $\mathrm{mm} \mathrm{Hg}$ after 20 weeks of gestation with proteinuria, with or without oedema, and no previous history of hypertension. It may occur at any time during the second half of pregnancy and at or within 48 hours after delivery ${ }^{1}$. It affects $8 \%$ of pregnant women and can lead to maternal and newborn death ${ }^{1}$. Further, the risk of preterm delivery and intrauterine growth retardation are increased $^{2}$. Most women with pre-eclampsia have a mild form near labour, and if they receive proper care, they and/or their fetuses are not at risk ${ }^{3}$.

Despite recent attempts to understand the pathophysiology of pre-eclampsia, there is still no definitive prevention and effective treatment other than termination of pregnancy ${ }^{2}$. During normal pregnancy, blood vessels of the placenta exchange the nutrients and waste material between mother and fetus ${ }^{4}$. Abnormal growth of the placenta leads to impaired function, especially in pre-eclamptic pregnancies that result from oxidative stress, hypoxia, and release of factors that cause endothelial dysfunction and inflammation ${ }^{4}$.

The risk factors for preterm labour (PTL) include maternal or infant medical conditions, genetic disorders, environmental factors, infertility treatment, social, economic and behavioural factors, 
and unknown causes ${ }^{5}$. The infant complications of PTL include respiratory distress syndrome, jaundice, prematurity, long-term brain dysfunction, pulmonary dysfunction, and ophthalmic disorders ${ }^{6}$. PTL and its short- and long-term complications are a serious problem that results in disability and increased health care costs ${ }^{7}$. The lack of precise knowledge of the mechanism of early onset of labour is a limitation in its effective treatment ${ }^{7}$. Use of modern techniques for preventing pregnancy complications is an important task in prenatal care ${ }^{8}$.

Pre-eclampsia has been associated with a 5\% reduction in birth weight and an increase of 4-times for small for gestational age (SGA) ${ }^{9}$. Conversely, the prevalence of large for gestational age (LGA) in the early stages of pre-eclampsia has been reported before the last two weeks of gestation ${ }^{10}$. Oxidative stress can also play a role in the pathogenesis of preeclampsia. The main source of active oxygen species (ROS) is the xanthine oxidase enzyme, which is mainly active in the liver. One hypothesis is that the increase in purine catabolism is due to placental hypoxia, which leads to an increase in the production of ROS in the mother's liver and releases into the mother's circulation, causing damage to the endothelial cells ${ }^{11}$.

Some studies have suggested that more calcium intake or low-dose aspirin may aid prevention or treatment of pre-eclampsia, but the results of these studies are not very positive, and most clinicians do not recommend them for women who are at lower risk $^{12}$. Considering its relatively high prevalence and associated complications, early diagnosis and treatment of pre-eclampsia can benefit both mother and child ${ }^{13}$. There are only a few studies on the fetal complications of PTL due to pre-eclampsia in the Iranian population, and the results of these limited studies are also controversial.

\section{Objectives}

To evaluate the neonatal outcomes of PTL due to pre-eclampsia, and to compare its complications with those of spontaneous PTL.

\section{Method}

A cross-sectional study was performed on 190 women with PTL attending the Persian Gulf Hospital of Bandar Abbas, Iran, from 2011 to 2016. After obtaining clearance from the Ethics Committee of the Faculty of Medicine (approval code: IR.HUMS.REC.1397.162), 190 cases of PTL of fewer than 37 weeks were selected randomly, according to the table of random numbers, from the medical records from 2011 to 2016 according to inclusion criteria. The first group consisted of 94 cases of PTL due to pre-eclampsia, and the second group included 96 women with spontaneous PTL. Data was collected via a checklist to record the days of admission to the NICU, the mean weight, height, and head circumference, the Apgar score in the first and fifth minutes, respiratory distress, jaundice (at least $5 \mathrm{mg} / \mathrm{dL}$ ). In the case of incomplete files, the investigation process was removed.

Statistical analysis: Quantitative information was presented as means, standard deviations, and numbers or percentages. Analysis of data was done using SPSS version 20. To compare the two groups in quantitative variables, we first examined their distribution in each group. In the case of normalization of these variables in each group, the independent t-test, Pearson correlation coefficient, Mann-Whitney's non-parametric tests and Spearman correlation coefficient were used. Due to the normalization of the data, only the parametric tests were used. Normality was determined by the Kolmogorov-Smirnov test. The significant difference was set at less than 0.05 .

\section{Results}

The mean ages of the mothers with and without preeclampsia were $27.06 \pm 7.7$ and $26.94 \pm 4$ years, respectively. This was not significant $(\mathrm{p}>0.05)$.

The characteristics of the infants in the studied group are shown in Table 1.

Table 1: Characteristics of the infants in the studied group

\begin{tabular}{|c|c|c|c|}
\hline Variable & $\begin{array}{l}\text { Preeclamptic group } \\
\qquad(n=94)\end{array}$ & $\begin{array}{l}\text { Spontaneous PTL } \\
\text { group }(n=96)\end{array}$ & P-value \\
\hline Birth weight in $\mathrm{kg}($ mean \pm SD) & $2.41 \pm 0.42$ & $2.62 \pm 0.42$ & 0.001 \\
\hline Length in $\mathrm{cm}($ mean $\pm \mathrm{SD})$ & $49.65 \pm 3.52$ & $50.52 \pm 3.16$ & 0.074 \\
\hline Head circumstance in $\mathrm{cm}($ mean $\pm \mathrm{SD})$ & $34.28 \pm 3.36$ & $35.33 \pm 1.22$ & 0.005 \\
\hline Infants hospitalized in NICU n (\%) & $63(67)$ & $42(45)$ & 0.001 \\
\hline Length of stay in NICU in days & $1.38 \pm 1.73$ & $0.56 \pm 1.27$ & 0.001 \\
\hline $\begin{array}{l}\text { Apgar score: At one minute } \\
\text { At five minutes }\end{array}$ & $\begin{array}{l}7 \\
8\end{array}$ & $\begin{array}{l}8 \\
9\end{array}$ & $\begin{array}{l}0.001 \\
0.001\end{array}$ \\
\hline Respiratory distress $\mathrm{n}(\%)$ & $23(24.4)$ & $16(16.6)$ & 0.18 \\
\hline Death $n(\%)$ & $9(9.5)$ & $3(3.1)$ & 0.068 \\
\hline Jaundice $\mathrm{n}(\%)$ & $78(82.9)$ & $45(46.8)$ & 0.001 \\
\hline
\end{tabular}

PTL: Pre-term labour 
Birth weights of infants of mothers with preeclampsia were significantly lower than birth weights in the spontaneous PTL group $(p=0.001$, $\mathrm{p}<0.01)$. However, the length at birth was not significantly different in infants of pre-eclamptic group compared to the spontaneous PTL group $(p=0.074, p>0.05)$. According to the independent $t-$ test, the head circumference was significantly lower in infants of pre-eclamptic group compared to the spontaneous PTL group $(\mathrm{p}=0.005, \mathrm{p}<0.01)$.

The number of infants hospitalised in the neonatal intensive care unit (NICU) was significantly higher in mothers with pre-eclampsia in comparison with the infants in the spontaneous PTL group $(p=0.001$, $\mathrm{p}<0.01)$. The length of stay in the NICU was significantly longer in infants of the pre-eclamptic group compared to the spontaneous PTL group $(p=0.005, p<0.01)$. The mean Apgar score in the infants of mothers with pre-eclampsia was significantly lower than in infants in the spontaneous PTL group in both the first and fifth minutes after birth $(\mathrm{p}=0.001, \mathrm{p}<0.01)$.

The Pearson Chi-Square test revealed that there was no significant difference in the numbers of babies developing respiratory distress in the 2 groups $(\mathrm{p}=0.18, \mathrm{p}>0.05)$. Also, based on the Pearson ChiSquare test, deaths in premature infants was not significantly different in the two groups $(\mathrm{p}=0.068$, $\mathrm{p}>0.05$ ). According to the Pearson Chi-Square test, the prevalence of jaundice in infants of mothers with pre-eclampsia was significantly higher than in infants of mothers undergoing spontaneous PTL $(\mathrm{p}=0.001, \mathrm{p}<0.01)$.

\section{Discussion}

PTL causes $70 \%$ of neonatal deaths, and its prevalence varies in different areas, being $5.6 \%$ in developed countries but in developing countries ranging from $1.8 \%$ to $16.7 \%{ }^{14,15}$. In Iran, the prevalence has been reported to be $4-10 \%{ }^{16}$. Complications due to PTL are common causes of death in neonates. According to studies, from 5\% to $15 \%$ of all deliveries result in preterm infants, and approximately $91 \%$ mortality and morbidity occur in preterm infants ${ }^{17}$. The birth rate of premature infants is $9-12 \%$ in America, $5-7 \%$ in Europe, and 5-9\% in developing countries ${ }^{18,19}$. This rate in Iran has varied in different studies and different parts of the country. In a study in Tehran, prevalence of PTL was $7.8 \%$, in Zanjan it was 7\%, and in Mashhad it was $16.4 \%{ }^{20-}$ 22. In a study by Khadem et al, prevalence of PTL was $54.4 \%$ in patients with pre-eclampsia and $25 \%$ in healthy mothers ${ }^{23}$. In a study by Nehbandani et al, PTL in mothers with pre-eclampsia was $29.2 \%$, while in the meta-analysis performed by Khadem et al, PTL was observed in $0.05 \%$ of women ${ }^{24}$. The reason for the difference in outcome may be the type of decision-making in the administration of preeclampsia. While other causes of neonatal morbidity and mortality have decreased, the complications of PTL have not yet been resolved and are currently considered the most important issue in neonatal medicine ${ }^{25}$. The results of our study showed that the number of days hospitalised in NICU among mothers with pre-eclampsia was higher than in the spontaneous PTL group. The study by Khadem et al. showed that mothers with pre-eclampsia, and healthy mothers were significantly different in terms of the length of stay in NICU. In their study, there were $8 \%$ admissions to the NICU by the control group compared to $31 \%$ admissions by the case group $^{23}$. The duration of hospitalisation was more than three days in the cases group ${ }^{23}$. In another study by Safari and Yazdanpanah, the prevalence of preeclampsia in the NICU group was $25.6 \%$ and $10.2 \%$ in the control group ${ }^{26}$. Similar results were found in a study by Cruz et al. where the length of stay in NICU was lowest in healthy mothers and increased in mild and severe pre-eclampsia groups ${ }^{27}$. Also, Basiri et al. demonstrated that pre-eclampsia was more prevalent in the non-survived neonate than in those hospitalised in NICU ${ }^{28}$.

In our study, the 1 and 5 minute Apgar scores in infants of mothers with pre-eclampsia were lower in comparison with the spontaneous PTL group. Similarly, in the study by Khadem et al. in mothers with pre-eclampsia and healthy mothers, there was a significant difference in the Apgar scores at 5 minutes after birth ${ }^{23}$. Tran et al. findings show that pre-eclamptic newborns had lower 1 minute Apgar scores than non-pre-eclamptic babies ${ }^{29}$. In a study by Fallahian et al. on the effects of high blood pressure in pregnant women on neonates in Taleghani Hospital in 1999, findings indicated that in the hypertensive group, the lower aphrodisiac was 9times more than the control group ${ }^{30}$. The study by Nehbandani et al. showed that the Apgar score below 7 at birth was related to the complications of neonates of mothers with pre-eclampsia ${ }^{24}$.

In our study, weight and head circumference in preterm infants of mothers with pre-eclampsia were significantly lower than those of spontaneous PTL group. However, the length at birth was not significantly different in preterm infants of mothers with pre-eclampsia compared to the spontaneous PTL group. In the study by Avorgbedor et al, although mean infant length at 2 months was less in the pre-eclamptic group than the control group, other growth and neurodevelopmental outcomes did not differ between the groups ${ }^{31}$. The study by Fallahian et al. showed that in pregnant mothers with hypertension, the weight of infants was 2 times higher than the control group ${ }^{28}$. A study by Balogun et al. revealed that women with preterm pre- 
eclampsia with severe features had significantly higher risk of fetal growth restriction when compared with those with the normal group ${ }^{32}$. These results are consistent with the study of Khadem et $a l^{23}$. Accordingly, our study findings suggested that attention to exact control of pre-eclampsia and avoidance of making rash decision for terminating pregnancy in mild pre-eclampsia could improve outcomes of neonates.

\section{Conclusions}

In this study on preterm infants, pre-eclampsia had a significant impact on NICU hospitalisation rate, length of stay in NICU, Apgar scores in first and fifth minutes, the incidence of jaundice, weight, and head circumference at birth, but not on the length of the baby or respiratory distress.

\section{References}

1. Rolnik DL, Wright D, Poon LC, O'gorman N, Syngelaki A, de Paco Matallana C, et al. Aspirin versus placebo in pregnancies at high risk for preterm pre-eclampsia. New England Journal of Medicine 2017; 377(7): 613-22. https://doi.org/10.1056/NEJMoa1704559 PMid: 28657417

2. Zeisler H, Llurba E, Chantraine F, Vatish M, Staff AC, Sennström M, et al. Predictive value of the sFlt-1: PlGF ratio in women with suspected pre-eclampsia. New England Journal of Medicine 2016; 374(1):13-22. https://doi.org/10.1056/NEJMoa1414838 PMid: 26735990

3. Sircar M, Thadhani R, Karumanchi SA. Pathogenesis of pre-eclampsia. Current Opinion in Nephrology and Hypertension 2015; 24(2):131-8.

https://doi.org/10.1097/MNH.0000000000000 105

PMid: 25636145

4. Parchem JG, Kanasaki K, Kanasaki M, Sugimoto H, Xie L, Hamano Y, et al. Loss of placental growth factor ameliorates maternal hypertension and pre-eclampsia in mice. Journal of Clinical Investigation 2018; 128(11):5008-17.

https://doi.org/10.1172/JCI99026

PMid: 30179860 PMCid: PMC6205389

5. English FA, Kenny LC, McCarthy FP. Risk factors and effective management of preeclampsia. Integrated Blood Pressure Control 2015; 8:7.

https://doi.org/10.2147/IBPC.S50641

PMid: 25767405 PMCid: PMC4354613
6. Ananth CV, Lavery JA, Friedman AM, Wright JD.: Maternal complications in relation to severe pre-eclampsia: impact of regionalization of care in the United States. American Journal of Obstetrics \& Gynecology 2016; 214(1):S260. https://doi.org/10.1016/j.ajog.2015.10.517

7. Tangren JS, Wan Md Adnan WA, Powe CE, Ecker J, Bramham K, Hladunewich MA, et al. Risk of pre-eclampsia and pregnancy complications in women with a history of acute kidney injury. Hypertension 2018; 72(2):4519. https://doi.org/10.1016/j.ajog.2015.10.517

8. Ananth CV, Lavery JA, Vintzileos AM, Skupski DW, Varner M, Saade G, et al. Severe placental abruption: clinical definition and associations with maternal complications. American Journal of Obstetrics and Gynecology 2016; 214(2):272-e1. https://doi.org/10.1016/j.ajog.2015.09.069 PMid: 26393335

9. Sõber S, Reiman M, Kikas T, Rull K, Inno R, Vaas $\mathrm{P}$, et al. Extensive shift in placental transcriptome profile in pre-eclampsia and placental origin of adverse pregnancy outcomes. Scientific Reports 2015; 5:13336. https://doi.org/10.1038/srep13336

PMid: 26268791 PMCid: PMC4542630

10. Zhang X, Xiao Y. The association between trimester-specific weight gain and severe preeclampsia/ adverse perinatal outcome in gestational diabetes mellitus complicated by pre-eclampsia: A retrospective case study. Diabetes Therapy 2019; 10(2):725-34. https://doi.org/10.1007/s13300-019-0589-3 PMid: 30838548 PMCid: PMC6437224

11. Huang QT, Chen JH, Hang LL, Zhong M. Activation of PAR-1/NADPH oxidase/ROS signaling pathways is crucial for the thrombininduced sFlt-1 production in extravillous trophoblasts: possible involvement in the pathogenesis of pre-eclampsia. Cellular Physiology and Biochemistry 2015; 35(4):1654-62.

https://doi.org/10.1159/000373979

PMid: 25824463

12. Tamblyn JA, Susarla R, Jenkinson C, Jeffery LE, Ohizua O, Chun RF, et al. Dysregulation of maternal and placental vitamin D metabolism in preeclampsia. Placenta 2017; 50:70-7.

https://doi.org/10.1016/j.placenta.2016.12.019

PMid: 28161064 PMCid: PMC5463036 
13. Fisher SJ. Why is placentation abnormal in pre-eclampsia?. American Journal of Obstetrics and Gynecology 2015; 213(4):S115-22. https://doi.org/10.1016/j.ajog.2015.08.042 PMid: 26428489 PMCid: PMC4592742

14. Ragasudha C, Madhavi AP, Sharon PS, Priya SS, Shehnaz S. A study of maternal deaths from pre-eclampsia and eclampsia in a tertiary care centre. International Archives of Integrated Medicine 2018; 5(1): 6-10.

15. Belay AS, Wudad T. Prevalence and associated factors of pre-eclampsia among pregnant women attending ante-natal care at Mettu Karl referal hospital, Ethiopia: crosssectional study. Clinical Hypertension 2019; 25(1): 14 .

https://doi.org/10.1186/s40885-019-0120-1 PMid: 31304042 PMCid: PMC6600877

16. Omani-Samani R, Ranjbaran M, Amini P, Esmailzadeh A, Sepidarkish M, et al. Adverse maternal and neonatal outcomes in women with pre-eclampsia in Iran. Journal of Maternal-Fetal \& Neonatal Medicine 2019; 32(2): 212-6.

https://doi.org/10.1080/14767058.2017.13766 43

PMid: 28871889

17. Tielsch JM. Global incidence of preterm birth. Nestle Nutrition Institute Workshop Series 2015; 81:9-15.

https://doi.org/10.1159/000365798

PMid: 26111559

18. Chisholm KM, Heerema-McKenney A, Tian L, Rajani AK, Saria S, Koller D, Penn AA. Correlation of preterm infant illness severity with placental histology. Placenta 2016; 39:61-9.

https://doi.org/10.1016/j.placenta.2016.01.012

PMid: 26992676 PMCid: PMC4819396

19. do Carmo Leal M, Esteves-Pereira AP, Nakamura-Pereira M, Torres JA, Theme-Filha M, Domingues RM, et al. Prevalence and risk factors related to preterm birth in Brazil. Reproductive Health 2016; 13(3):127. https://doi.org/10.1186/s12978-016-0230-0 PMid: 27766978 PMCid: PMC5073982

20. Davari Tanha F, Valadan M, Kave M, Bagher zadeh Jalilvands HM. Prevalence and risk factors of recurrent preterm delivery in three hospitals of Tehran University. Journal of Tehran University of Medical Sciences 2007; 65(2):34-9.
21. Sohrabi D, Ghanbari Gorgani M. Study of risk factors during pregnancy on preterm birth in women-ValiAsr Hospital Zanjan-2007. Journal of Oroomiie Nursing and Midwifery School 2011; 9(2):

22. Lotf Alizadeh M, Mohammadzadeh A, Kamandi SH, Bagheri S. Prevalence and risk factors of preterm labor in Imam Reza Hospital 2003-2004. Iranian Journal Of Obstetrics, Gyneocology And Infertility. 2005; 8:93-100.

23. Khadem N, Shahfarhat A, Ghomian N, Ebrahimzadeh S. Prevalence of preterm labor and it's complications in neonates of women with preeclampsia-eclampsia in emam reza hospital. Journal of Ardabil University of Medical Sciences 2007. 7(4): 368-74.

24. Nehbandani S, Koochakzai M, Mirzaee F, Moghimi F. Prevalence of preeclampsia and its maternal and fetal complications in women referring to Amiralmomenin Hospital of Zabol in 2014-2015. Journal of Birjand University of Medical Sciences 2018; 24(4): 306-12.

25. Kharaghani R, Cheraghi Z, Esfahani BO, Mohammadian Z, Nooreldinc RS. Prevalence of pre-eclampsia and eclampsia in Iran. Archives of Iranian Medicine 2016; 19(1):

26. Safari M, Yzdan panah B. Prevalence of preeclampsia and its correlated maternal and fetal complications, Emam Sajjad Hospital, Yasuj, 2001 Journal of Shahrekord University of Medical Sciences 2003; 5(2) :47-53.

27. Cruz MO, Gao W, Hibbard JU. Obstetrical and perinatal outcomes among women with gestational hypertension, mild pre-eclampsia, and mild chronic hypertension. American Journal of Obstetrics and Gynecology 2011; 205(3):260-e1.

https://doi.org/10.1016/j.ajog.2011.06.033

PMid: 22071056

28. Basiri B, Ashari FE, Shokouhi M, Sabzehei MK. Neonatal mortality and its main determinants in premature infants hospitalized in neonatal intensive care unit in Fatemieh hospital, Hamadan, Iran. Journal of Comprehensive Pediatrics 2015; 6(3): https://doi.org/10.17795/compreped-26965

29. Tran PL, Robillard PY, Dumont C, Schweizer C, Omarjee A, Iacobelli S, et al. Recurrent or first pre-eclampsia in multiparae: a casecontrol study of singleton pregnancies in Reunion Island. European Journal of 
Obstetrics \& Gynecology and Reproductive Biology 2019;

https://doi.org/10.1016/j.ejogrb.2019.06.013

PMid: 31234061

30. Fallahian $M$, Emadosadati N. Effects of hypertension of pregnant mothers on neonates, Taleghani Hospital-1999. Journal of Reproduction and Infertility 2001; 2(3): 48-53.

31. Avorgbedor F, Silva S, Merwin E, Blumenthal JA, Holditch-Davis D. Health, physical growth, and neurodevelopmental outcomes in preterm infants of women with hypertensive disorders of pregnancy. Journal of Obstetric, Gynecologic, and Neonatal Nursing. 2019; 48(1):69.

https://doi.org/10.1016/j.jogn.2018.10.003

PMid: 30502314
32. Balogun OA, Khanagura RK, Kregel HR, Amro FH, Sibai BM, Chauhan SP. Preterm pre-eclampsia with severe features: Composite maternal and neonatal morbidities associated with fetal growth restriction. American Journal of Perinatology 2018; 35(8):785. https://doi.org/10.1055/s-0037-1617456 PMid: 29298455 